\title{
Cuerpos femeninos en movimiento o acerca de los significados sobre la salud y la enfermedad a fines del siglo XIX en Argentina
}

Pablo Ariel Scharagrodsky*

Resumen: El siguiente artículo analiza a las prácticas corporales -la educación física escolar, las gimnasias, los juegos, los bailes, los paseos, las caminatas y ciertos sports- en la Argentina a finales del siglo XIX como un terreno conflictivo en el que distintos actores y grupos sociales pusieron en circulación, distribución, transmisión y producción un conjunto complejo y heterogéneo de tópicos vinculados con el cuerpo y su funcionamiento, la salud y la enfermedad, la diferencia sexual y la feminidad. Centramos la atención, desde el discurso médico, en una de las enfermedades más mencionadas en la época: la histeria. Asimismo, analizamos el significado que tuvo la salud para las niñas y mujeres que experimentaron la práctica de la gimnasia y de los diferentes ejercicios físicos prescriptos. El interrogante central es: ¿cómo y por qué el registro médico conceptualizó el par salud/enfermedad en las niñas y mujeres en el marco de ciertas prácticas corporales?

Palabras claves: prácticas corporales; gimnasia; femineidad; maternidad; histeria.

\section{Female bodies in movement or health and illness meanings at the end of the XIX century in Argentina}

The following article analyzes the body practices - the school physical education, gymnastics, games, dances, rides, walks and certain sports - in Argentina at the end of the nineteenth century- as a conflictive field where different actors and social groups spread, distributed, transmitted and produced a complex and heterogeneous group of topics linked to the body and its functioning, health and illness, sexual difference and femininity. From a medical point of view, we drew our attention on one of the most commonly mentioned illnesses more at that time: hysteria. We also analyzed the meaning of health for the girls and women that experienced the practice of gymnastics and different prescribed physical exercises. The main question is: how and why did the medical recordconceptualize both health and illness in the frame of certain body practices for girls and women?

Key words: body practices; gymnastics; femininity; maternity; hysteria.

\footnotetext{
Docente investigador en la Licenciatura en Educación en la Universidad Nacional de Quilmes (UNQ) y en el Profesorado en Educación Física en la Universidad Nacional de La Plata, Argentina. pas@unq.edu.ar
} 
En la Argentina de finales del siglo XIX las prácticas corporales -la educación física escolar, las gimnasias, los juegos, los bailes, los paseos, las caminatas y ciertos sports- estuvieron fuertemente visibilizadas por diferentes actores, instituciones, grupos sociales, discursos y saberes. Entre ellos sobresalió el discurso y la corporación médica, que al amparo del higienismo (Nouzeilles, 2000; Salvatore, 2001; Di Liscia, 2004) se convirtió en un fuerte 'orientador' de comportamientos individuales y sociales creando un determinado estilo de 'vida saludable'.

Este estilo de 'vida saludable' se interesó por una serie de tópicos y temas entre los que se incluyó recurrentemente al dispositivo de la sexualidad articulado con diversos aspectos de la vida cotidiana, destacándose la crecientemente promocionada 'cultura física' decimonónica. En particular, las 'cuestiones femeninas' y su relación con las actividades y ejercicios físicos abundaron en distintas disquisiciones y problematizaciones. Las mismas estuvieron atravesadas por una serie de registros médicos en donde la anatomía, la fisiología y la ginecología tuvieron una fuerte influencia y definieron una específica política sexual hegemónica sobre el movimiento adecuado, correcto y deseable de los cuerpos femeninos. A finales del siglo XIX las mujeres, especialmente urbanas y de clase media, no podían moverse, desplazarse, correr, saltar, caminar o gesticular de cualquier manera. Ya sea en las escuelas, en los parques, en las plazas públicas, en los gimnasios o en los clubes se fue configurando un cierto orden corporal 'femenino'.

Este proceso de regulación y control de los cuerpos femeninos ocurrió en momentos en que se destacaron dos grandes acontecimientos en la Argentina. Por un lado, el Estado nacional y el sistema de instrucción público nacional estaban en pleno proceso de construcción y de consolidación. (Puiggrós, 1990, 1996; Narodowski, 1999) Por el otro, una serie de reordenamientos y reacomodamientos referidos a los ordenes generizados se produjeron e intensificaron como consecuencia de la emergencia de los diferentes feminismos de la primera ola (sufragio femenino, mejores condiciones de trabajo, maternidad, etc.), de ciertos cuestionamientos a tópicos considerados por la 'elite masculina' conservadora como incuestionables en aquella época (sexualidad, 'instinto maternal', moral femenina, funcionamiento del cuerpo femenino, etc.) o de determinadas fobias a la inversión sexual en un contexto en el que la homosexualidad apareció como uno de los problemas más graves de infección de los Estados modernos (homosexualidad, deseo, placer, etc.). (Salessi, 1995; Barrancos, 1990, 2002; Lavrin, 1998)

Teniendo en cuenta lo anterior, el siguiente artículo analiza a las prácticas corporales como un terreno altamente conflictivo en el que distintos actores, instituciones y grupos sociales pusieron en circulación, distribución, transmisión y producción un conjunto complejo y heterogéneo de tópicos vinculados con el cuerpo y su funcionamiento, la salud y la enfermedad, la diferencia sexual y, muy especialmente, la feminidad. Al ser la medicina quien dio sustento y aval a 
estos y otros tópicos, proponemos como fuentes de análisis las tesis de medicina producidas en dicho período. Según Nouzeilles las tesis médicas universitarias sobre fisiología, ginecología, patologías e higiene de las mujeres abundaron hacia fines del siglo XIX. Entre 1875 y 1905 fueron aproximadamente entre 15 y 25 por ciento. (Nouzeilles, 1999, p. 102) Dichas tesis pueden ser leídas como parte central de la episteme que circuló, se enseñó y se transmitió entre la corporación médica argentina. Dicha corporación tuvo un rol central en la definición de políticas educativas y escolares.

En consecuencia, las preguntas que guían el presente artículo son las siguientes: ¿cómo y por qué el registro médico contribuyó a configurar una cierta feminidad?, ¿cómo y por qué el registro médico conceptualizó el par salud/enfermedad en las mujeres en el marco de ciertas prácticas corporales? y ¿̨contra qué modelos femeniles se enfrentó el registro médico?

\section{Higienismo, cultura física y femineidad}

La corriente higienista durante todo el siglo XIX estuvo fuertemente motorizada en gran parte de los países europeos en razón de las tensiones derivadas de la relación entre riqueza y salud. "Esta problemática representó el punto de partida desde el cual los higienistas elaboraron sus estrategias, por lo que puede afirmarse que fueron los primeros traductores de aquella importante tensión entre riqueza y salud". (Gonzálies Leandri, 1999, p. 59)

Para disminuir estas y otras tensiones, a finales del siglo XIX la corporación médica argentina inserta en el Estado se convirtió, paulatinamente, en consejera de la política pública, implementando un conjunto de medidas profilácticas como obras de saneamiento, ensanche de calles, construcción de nuevas plazas, parques y paseos públicos, dispensarios médicos y, también, la estimulación de 'mucha gimnasia' y paseos al aire libre. Asimismo, todas estas acciones se configuraron en un contexto en el que las cuestiones de orden económico y social dieron cada vez mayor prioridad al capital humano como condición necesaria para la grandeza de la nación argentina. Como señala Nari, "la medicina social se construyó sobre un conflictivo campo científico-social cruzado por los costos humanos, cada vez más evidentes, de los procesos de industrialización y urbanización, y por el reemplazo de la teoría humoral de la enfermedad por la bacteriana. La medicina social se interesó por el orden económico y social al valorizar la vida humana, la población como capital 'humano', indispensable para la 'grandeza nacional'. El medio se presentaba como el foco principal de atención”. (Nari, 2004, p. 107) Desde allí debían partir las políticas curativas y preventivas siendo la 'cultura física' una parte pequeña pero no menor en el entramado del discurso médico hegemónico. 
Lo concreto fue que lentamente el higienismo atravesó todo la red social incluida la escolar. Desde fines del siglo XIX y principios del XX el poder de la práctica y el lenguaje médico en la trama escolar se manifestó muy claramente. Entre las razones, Puiggrós menciona "la prioridad que tomaba el tema del cuerpo, en una población inmigrante que veía bruscamente cambiadas sus condiciones de vida, sus parámetros y sus hábitos higiénicos, alimenticios, de relación sexual y social”. Asimismo, "la caracterización de la gran masa de los educandos como susceptibles de enfermar física, moral, mental y espiritualmente, o como enfermos de diversas categorías, fue su condición necesaria”. (Puiggrós, 1990, p. 118)

Paralelamente, a finales de los ' 80 del siglo XIX se consolidaron los estudios e investigaciones relacionados con la fisiología de los ejercicios físicos provenientes, fundamentalmente, de Francia. De esta manera, la circulación de la producción vinculada con la higiene física y su relación con determinadas prácticas corporales (especialmente la gimnasia) adquirió mayor visibilidad a través de las tesis de medicina y, también, amplia difusión en las revistas de educación más importantes de la época. Todo ello avalado por las recientes sanciones de las leyes de educación obligatoria en Argentina, como la ley 888 en la provincia de Buenos Aires en 1875 y la ley 1420 en capital y territorios nacionales en 1884; las cuales incorporaron como obligatoria la práctica de ciertos ejercicios físicos y gimnasias. Una importante cantidad de tesis médicas argentinas proclamaron la nueva 'era científica de la higiene' y su necesaria inserción en el ámbito escolar, así como en otros espacios urbanos como las plazas, los parques, los clubes y los gimnasios.

Este contexto de afianzamiento del monopolio médico, permitió a dicho sector incidir sobre las prácticas cotidianas entre las que aparecieron recurrentemente los ejercicios físicos y las diferentes prácticas corporales. La inculcación de los ejercicios físicos se entremezcló con aspectos vinculados con el bienestar moral del individuo, la raza, la familia y la nación, un especial estilo de vida, la regulación de un tipo particular de vivienda, el dictado de leyes sobre cantidad de horas de trabajo permitidas, campañas contra ciertas enfermedades (viruela, fiebre amarilla, cólera, tuberculosis, sífilis $)^{1}$, planes para el cuidado de los niños, regulaciones vinculadas con la maternidad, propuestas eugenésicas con el fin de mejorar la fuerza productora de la población y definición de programas educativos con el fin de mejorar las prácticas sanitarias e higiénicas de los individuos y de la población, especialmente de la clase trabajadora.

I. La Argentina en construcción, sufrió repetidas epidemias de cólera y fiebre amarilla en diferentes años, entre ellos $\mid 867$, I $87 \mid$ y $\mid 886$. Sobre estos sucesos se inscribieron un conjunto de temores vinculados a la degeneración física y moral de la población y, a la vez, un abanico variado de respuestas terapéuticas y preventivas, entre las que se destacaron la necesidad de incorporar distintas prácticas corporales a la vida cotidiana como la gimnasia, las caminatas y los paseos al aire libre.

Pro-Posiçóes, Campinas, v. 22, n. 3 (66), p. 97-110, set./dez. 2011 
La corriente higienista incorporó a su 'natural' trilogía (aire, sol y agua) la práctica de los ejercicios físicos. Vale decir que, al 'aire puro', a la luz solar, a las superficies lisas y lavables, al color blanco, al rechazo de los materiales porosos, debían acompañarles los ejercicios físicos con sus múltiples variantes. Pero ¿por qué aparecieron las mujeres como destinatarias fundamentales de dichas prácticas?, ¿cómo se construyó la diferencia sexual femenina en las distintas prácticas corporales prescriptas? y ¿qué significado tuvo el concepto de salud/enfermedad en las niñas y mujeres durante las prácticas corporales prescriptas?

\section{La gimnasia es saludable si produce madres fuertes y fecundas}

Las tesis médicas de finales del siglo XIX, a la hora de problematizar la 'cuestión femenina', encontraron un argumento central para intervenir sobre sus cuerpos: la maternidad. Esta preocupación no fue menor y atravesó la mayoría de las tesis médicas referidas a las niñas y mujeres. Las políticas sanitarias identificaron al cuerpo femenino y a su 'misteriosa' constitución e intervinieron sobre el mismo en nombre del futuro y la grandeza de la nación, del provenir de la raza y del aumento de la riqueza económica vinculada fundamentalmente a la fuerza de trabajo y al naciente ejército argentino.

La maternidad como único destino supuestamente inscripto en el cuerpo femenino atravesó todos los discursos y prácticas sociales de la época y la educación física y demás prácticas corporales -escolares o extraescolares- no estuvieron ausentes de tales consideraciones. Desde pequeñas las niñas debían prepararse para dicha función siendo los juegos, las danzas y cierto tipo de ejercicios físicos los más adecuados para lograr dicho objetivo:

Otro punto de vista bajo el cual debe considerarse á los juegos, es el desarrollo de lo que podría llamarse el sentido maternal y el sentido doméstico. La niña, sér amante y destinado á serlo mas aún, busca los juegos en que ejercitará esta facultad naciente; amistades infantiles y fraternales, trabajos de aguja, juegos sedentarios y tranquilos, caricias y adornos prodigados a ese vano simulacro de la forma humana, con el cual la niña preludia el dulce oficio de madre y hace una graciosa incursión en el porvenir'; y que es el vago instinto de la maternidad que se anuncia y se ensaya ya. Puede decirse lo mismo de los juegos que la niña anuncia el despertar del sentimiento doméstico [...] la danza, acompasada, científica, sometida a reglas, tiene también su valor en la educación de la niña". (Ramos Mejía, 1898, p. 37-38).

Ella tiene su misión reproductora, de ella depende la virilización de una raza, la moralidad de un estado, el valor 
de sus hijos. Eduquémosla sana de cuerpo, pura de alma y habremos conseguido realizar este ideal. (Rawson de Dellepiane, 1892, p. 11)

Este mensaje 'maternal' en un cuerpo sano, fuerte y fecundo no fue nuevo. En realidad, la fabricación del 'instinto maternal' en las mujeres formó parte de un compulsivo discurso, el cual se manifestó en Occidente desde finales del siglo XVIII. Como señala Badinter, el amor maternal adquirió un nuevo significado en el último tercio del siglo XVIII en Occidente. La imagen de la madre, de su función y de su importancia, sufrió un cambio radical. Abundaron las publicaciones que aconsejaron a las madres ocuparse personalmente de sus hijos y les 'ordenaron' que les den el pecho. Le crearon a la mujer la obligación de ser ante todo madre, y engendraron un mito que doscientos años más tarde seguiría más vivo que nunca: el mito del instinto maternal, del amor espontáneo de toda madre hacia su hijo. La novedad respecto de los siglos anteriores residió en la exaltación del amor maternal como valor simultáneamente natural y social, favorable a la especie y a la sociedad. A fines del siglo XVIII, para algunos lo esencial no fue ya tanto formar sujetos dóciles como sujetos a secas; sino producir seres humanos que fuesen la riqueza del Estado. Para lograrlo, fue preciso impedir a toda costa la sangría humana y la enorme cantidad de muertes de los niños en su primera infancia. El nuevo imperativo fue la supervivencia de los niños. (Badinter, 1981)

En este contexto, la gimnasia decimonónica y las demás prácticas corporales (juegos, danzas, paseos, caminatas, ejercicios físicos moderados, etc.) contribuyeron a formar cuerpos femeninos sanos y preparados para el oficio de la maternidad; fin supremo de la vida de cualquier mujer considerada 'normal' en aquella época. De alguna manera, la regeneración y la degeneración física, social y moral pasaron a ser responsabilidad de las mujeres quedando sujetadas al poder médico masculino y a las políticas higiénicas del Estado.

Esto último se intensificó en la Argentina por la fuerte confianza en el medio ambiente como mejorador y transformador de los cuerpos. Las teorías eugénicas dieron mayor visibilidad a las prácticas corporales y sus funciones perfeccionadoras. Como señala Nari, "en Argentina los conflictos específicos, seleccionaron y reformularon las teorías eugenésicas, siendo el 'transformismo' uno de los rasgos más característicos de la eugenesia local. La confianza en la posibilidad de transformación de los individuos y las 'razas' a partir de la adquisición de caracteres del medio y, luego, su transmisión por herencia estrechó las posibilidades de recepción de la eugenesia 'negativa'. El transformismo apostó a la centralidad del medio como palanca de cambio. El problema no sólo era mejorar la calidad de los que estaban o de los que llegaban sino aumentar cuantitativamente a los nacidos en el país, y que éstos sobrevivieran en un medio controlado sanitaria y educacionalmente". (Nari, 2004, p. 36-38) 
En este marco, entre la batería de acciones dirigidas a modelar y desarrollar cuerpos femeninos fuertes, armoniosos y, especialmente, fecundos emergió la educación física y la gimnasia. (Scharagrodsky, 2007) Sin embargo, la misma no debía traspasar ciertos límites so pena de virilizar a las mujeres, ni trastocar su verdadera 'esencia femenina' ni subvertir su futuro destino sexual y social:

Desgraciadamente en todas, casi sin excepción ninguna, la educación física está tanto más descuidada cuanto que los maestros creen de buena fé, que se preocupan de ella. Cuanto se equivocan! He sido maestro, he visto y conozco como se enseñan esos ejercicios ritmicos, que á manera de gimnasia, se practican en nuestras escuelas y, en verdad, ningun buen resultado puede esperarse de ellos [...] lejos de despertar en las niñas argentinas la aficion á los ejercicios campestres; á los paseos á pie, al salto, á la carrera, las familias creen que semejantes ejercicios son solamente para los varones y de ninguna manera buenos para ellas. No es que deseamos para la mujer argentina la educación varonil de los jóvenes pero entre estos ejercicios tan fuertes y las ridículas maniobras de nuestros ejercicios gimnásticos cabe un justo medio que podía observarse en alguna escuela inglesa de niñas que funciona en esta ciudad (Balbastro, 1892, p. 60-61).

Entre la gimnasia 'ridícula' y sin efectos sobre el cuerpo femenino y la posible virilización del mismo, las prescripciones médicas dibujaron los contornos del 'buen ejercicio femenil'. Este proceso adquirió mayor visibilidad a partir de la pubertad femenina considerada una etapa central pero a la vez riesgosa en la vida de las mujeres. Antes de ese gran momento, se suponía que las niñas y los niños no tenían grandes diferencias biológicas. Sin embargo, a partir de este momento la propia interpretación médica generizó a los cuerpos femeninos, naturalizó su supuesta fragilidad y debilidad corporal y esencializó comportamientos derivados de sus genitales; asignándole ciertas enfermedades producto de los cambios orgánicos:

La pubertad, considerada por algunos como la edad del matrimonio y la procreación, convierte á la niña en un ser cuyo organismo reclama para sí una gran actividad [...] Hasta esa época -la pubertad-, bien pocas son las diferencias que separan uno y otro sexo [...] la mujer suaviza y le imprime armonía a su voz, las formas femeninas se acusan más y más; las caderas sufren su consiguiente ensanchamiento, los miembros se redondean, se llenan de contornos y la silueta se torna femenina. Esto genera un aumento de energías que rompe el equilibrio, el cuerpo se resiente y las enfermedades aparecen [...] La niña en la pubertad se muestra reservada, indolente 
perezosa, se fatiga pronto y se sofoca al menor esfuerzo; deja sus distracciones infantiles, para volverse en extremo afectuosa, exagerando los sentimientos de amistad; se impresiona fácilmente excitando su cerebro y su nerviosidad empieza á desenvolverse ó se acentúa, cuando por herencia se han legado órganos ya enfermos [...] La debilidad psíquica hace que las enfermedades mentales, en esta edad de la vida, tengan una marcada preferencia (ÚBEDA, 1902, p.33-36).

El cuidado sobre ciertas partes del cuerpo se hizo evidente. La pelvis y el abdomen se convirtieron en el foco de atención de todas las actividades físicas. La menstruación resumió la relación con el binomio salud/enfermedad. El resguardo de estas partes mostró la jerarquización del cuerpo femenino a la hora de ejercitarlo físicamente. Sin embargo, detrás de esta atención existió a finales del siglo XIX una enfermedad que había que contener y que se diseminaba en todas las niñas y mujeres. El útero sería el responsable de tal 'desorden corporal' y la terapéutica incluyó a ciertas prácticas corporales como la gimnasia y determinados ejercicios físicos (Gay, 1992; Varela, 1997).

Nacida para ser madre lleva en su seno la cuna del linage humano y en su pélvis se aloja el más misterioso de los órganos -el útero- que hace de la mujer un ser especial". (BALBASTRO, 1892, p. 12) "De los muchos órganos que nos presenta el organismo humano, en ninguno se destaca tanto la nobleza, como en el útero y los ovarios, cuya sensibilidad es tan esquisita, que basta la menor emoción para que en un momento dado, en él repercuta de un modo notable (...) puedo decir que el útero y los ovarios son los reguladores del estado fisiológico de la mujer (Garbiso, 1889, p. 12).

\section{Ejercitando el útero o como 'calmar' a las niñas}

El útero se convirtió en una de las obsesiones médicas más importantes en las últimas décadas del silgo XIX. De hecho, una epidemia fue declarada con gran preocupación por parte del discurso médico hegemónico. Apareció con fuerza la histeria como la enfermedad de las mujeres. La educación física, la gimnasia y demás prácticas corporales se convirtieron en parte de la compleja terapéutica sobre esa temible enfermedad.

Si la mujer sana fue aquella que aprendió el difícil oficio de la maternidad respetando los canones morales comúnmente aceptados sobre la femineidad, no desviándose de la elección sexual heteronormativa, no cuestionando las relaciones de poder, la división 'sexual' del trabajo y la división de tareas y no convirtiéndose 
en políticamente disidente; las mujeres enfermas fueron aquellas que no aceptaron estos mandatos sociales y culturales.

Muchas enfermedades circularon en el imaginario de fines de siglo XIX. Entre las enfermedades más mencionadas aparecieron la tuberculosis, la escrofulosis, la escoliosis o las constipaciones de diverso tipo. Sin embargo, la que primó en el discurso médico referido a las mujeres fue la histeria. Como señala Nouzeilles, "el modelo hermenéutico del cuerpo diferente dominante en el fin del siglo XIX se centró casi exclusivamente en las prácticas decodificadoras de la histeria, entendida sobre todo como un lenguaje corporal anómalo propio de las mujeres y su equívoca inserción en la normalidad periférica". (Nouzeilles, 1999, p. 99)

Esta enfermedad no era nueva, ya que se remontaba a la antigüedad. Como señala Chauvelot "los médicos de antaño tenían frente a sus histéricas dos preocupaciones: alimentar el órgano hambriento y persuadirle de que volviera a su lugar. Para alimentarle era necesario, casar a las vírgenes y volver a casar a las viudas. Para persuadirle a recuperar su lugar en la pelvis había que engañarle, seducirle. O bien se actuaba desde arriba haciéndole ingerir a la paciente productos nauseabundos, o haciéndole respirar olores pútridos, o bien se hacía penetrar en su vagina dulces y suaves perfumes balsámicos". "Esta noción de útero migrante tan sensible a los perfumes va a perdurar durante siglos, hasta Ambroise Paré, quien fabricó, para uso de las histéricas, un speculum con agujeros para asegurar la penetración de los vapores aromáticos en el interior del conducto vaginal, que, sin eso, no sería más que una cavidad virtual. Por lo demás los balsámicos con fuerte olor como la valerina eran considerados como antihistéricos específicos en el Manual de farmacología publicado en Filadelfia en 1918" (Chauvelot, 2001, p. 11).

La histeria fue representada como perturbaciones cuyos orígenes provenían del útero. Efectivamente, el termino 'histeria' derivaba del vocablo griego hystera, o útero. Esta enfermedad, a finales del siglo XIX, apareció recurrentemente citada en las tesis de medicina, incluyendo a aquellas que hicieron alusión directa o indirectamente a la gimnasia y a la educación física:

De todas las enfermedades a que está espuesta la mujer ninguna es tan frecuente, ninguna ejerce tanta influencia no solamente en el individuo, sinó también en la sociedad, como la histeria" (Balbastro, 1892, p. 70).

$\mathrm{Al}$ principio la histeria fue circunscripta a las clases altas. Luego, cuando las mujeres subversivas (feministas, socialistas, anarquistas, comunistas, etc.) reclamaron otro tipo de orden social y sexual, casualmente, también fueron imputadas de sufrir esta 'terrible epidemia'. Según Nouzeilles, esta enfermedad estuvo fuertemente relacionada con los incipientes cambios vinculados con el lugar social de las mujeres a finales del siglo XIX. Frente a los reclamos y las reivindicaciones de 
muchas mujeres y "dado que una de las funciones normalizadoras de la medicina giraba en torno a la definición de los roles sexuales y la salud de la familia nuclear; la comunidad médica argentina diagnosticó una epidemia de histerismo entre las mujeres, causada teóricamente por los excesos genésicos (relaciones prematrimoniales, masturbación), el lujo (ropa, maquillaje), y por la fatiga cerebral derivada de la asistencia a lugares públicos (teatros, paseos, bailes, asambleas obreras, manifestaciones) y de esfuerzos intelectuales supuestamente incompatibles con la predisposición innata a la enfermedad del sexo débil y sus delicados órganos genitales" (Nouzeilles, 1999, p. 106).

El nerviosismo 'natural' de las mujeres y sus pasiones poco controlables fueron parte de la descripción de esta enfermedad. La caracterización de una mujer histérica fue variada: rápido desenvolvimiento del cerebro, talento precoz, gusto refinado y culto, vivacidad fascinadora, impresionabilidad y sensibilidad exageradas, gran debilidad del sistema muscular, marcada predisposición a padecer enfermedades nerviosas y de los órganos genitales, hábitos sedentarios, excesiva movilidad del carácter, apasionamiento, desequilibrio nervioso, mentirosas, exageradas y al borde de la locura. "No locas pero si fronterizas de esa región incierta" (Balbastro, 1892, p. 68). Sobre esta caracterización de la histeria emergieron un conjunto de manifestaciones también diversas: palpitaciones, agitación, trastornos menstruales, hipocondría, dolores de cabeza, meteorismo, alucinaciones, sofocación, inapetencia, calor, frío, convulsiones, súbitos cambios de carácter y, en algunos casos, perversiones de todos los sentidos.

Para enfrentar esta verdadera 'epidemia' el discurso médico hegemónico creó toda una batería de procedimientos re-encauzadores de ese lenguaje corporal considerado como anómalo, desenfrenado, indecente y peligroso. Junto con la gimnasia y la educación física se prescribieron otros tratamientos contra la histeria como la administración de psicofármacos, el aislamiento, la cirugía ginecológica (ovariotomías, salpingoovariectomías, raspados, etc.), la sugestión hipnótica y/o los masajes. El fin no sólo fue calmar las contracciones corporales confusas e irregulares, sino el significado sexual que pusieron en circulación, producción y transmisión.

Una de las causas predisponentes más comunes entre nosotros de las enfermedades genitales que contínuamente aflijen á las señoras, es indudablemente la falta de ejercicio y privación de aire, que como sabemos, deteriora la sangre, debilita el sistema muscular exalta al nervioso. Observamos las costumbres de la mujer particularmente en nuestra sociedad (Solá, 1888, p. 53).

Los ejercicios físicos tienen ademas la inmensa ventaja de calmar el sistema nervioso, al mismo tiempo que activan las grandes funciones del organismo, fortifican los músculos debilitados por actitudes viciosas ó por una larga inacción,

Pro-Posiçôes, Campinas, v. 22, n. 3 (66), p. 97-110, set./dez. 2011 
dan soltura y gracia a los movimientos, aumentan el campo respiratorio y mantienen la rectitud de la columna vertebral (Ramos Mejía, 1898, p. 63).

La depravación de movimientos corporales irregulares debía ser contenida a partir de ejercitaciones pasivas. Era necesario calmar el sistema nervioso supuestamente excitado. En realidad, la pasividad, como primer paso, significo todo lo contrario a la excitación nerviosa y todas las asociaciones sexuales que ello implicaba. Una de las causas de este estado fue atribuido a la menstruación:

Muchas veces, el desorden menstrual es la causa de la neurosis [...] Las perturbaciones de la menstruación conducen a la locura, producen diversas neurosis designadas bajo diferentes nombres de nerviosismo, histeria, estado nervioso (Martínez, 1881, p. 39)

Para gran parte del discurso médico la menstruación resumía buena parte de los males de las mujeres y era considerada como una enfermedad propiamente femenina. Se suponía que la llegada de la pubertad y la menstruación en la mujer desencadenaban síntomas morbosos, todos referidos al sistema nervioso: neuralgias, ataques histeriformes, cambios de carácter, etc (Nouzeilles, 1999). Esto estaba legitimado por la propia forma de entender a los cuerpos femeninos desde el discurso médico hegemónico. De hecho, a finales del siglo XIX "la vida de las mujeres se leyó a partir de su cuerpo, específicamente de sus genitales y aparato reproductivo. Se suponía que el útero hacía de la mujer un ser peculiar, un ser aparte" (Nari, 2004, p. 108).

En este contexto, apareció de la mano de la fisiología del ejercicio y de la ginecología decimonónica, un conjunto de prescripciones sobre el ejercicio físico y la gimnasia para las niñas y las mujeres referido a la cantidad, intensidad, gradación y modalidad de los mismos. Sin embargo, detrás de esta combinación de saberes existieron múltiples fantasías, temores y prejuicios de parte de ciertos varones, sobre las mujeres y su sexualidad. En nombre de la fisiología del ejercicio las niñas y mujeres debieron regular adecuadamente sus energías y no malgastarlas; especialmente en ciertos períodos críticos como la menstruación.

Necesario es que sepan nuestras jóvenes que en el momento de sus reglas, hay que evitar todo traumatismo, que toda conmoción, que todo movimiento exagerado repercute de una manera fastidiosa en los órganos que pasan por una faz de congestión transitoria (Úbeda, 1902, p. 81).

La congestión transitoria de los órganos genitales se convirtió en un argumento recurrente que obturó y limitó el universo kinético y moral de las niñas y mujeres. 
Pero más allá de este momento corporal de las niñas, se prohibió insistentemente que las mismas experimenten saltos en profundidad, carreras de fondo, ejercicios de velocidad y de fuerza, ciertos juegos, determinados deportes, el uso de la bicicleta o la práctica de la equitación. No sea cuestión que se desprendan sus delicados órganos o se convirtiesen en 'machonas', perdiendo su encanto sexual y su 'natural' función social. Asimismo, las niñas se vieron impedidas de realizar ciertos movimientos como separar las piernas formando un ángulo de 180 grados, patear una pelota de 'fútbol', ejecutar ciertas acciones motrices como trepar, escalar o golpear, ejecutar contactos corporales considerados bruscos e indecentes o realizar respiraciones enérgicas, y exageradas. Todo ello contribuyó a silenciar cualquier señal de disidencia corporal y sexual.

De allí que la moderación durante los ejercicios físicos fuese el criterio más mencionado posibilitando el estereotipo del movimiento femenino suave, lento, grácil e íntimo. La moderación, un término con fuertes connotaciones religiosas, organizó al cuerpo femenino en movimiento y definió un universo moral y sexual permitido y correcto. Moderación en los juegos, en la gimnasia y en las ejercitaciones físicas. La moderación de los movimientos 'femeninos', implicó metafóricamente moderación de sus órganos genitales, de su expresividad y de sus deseos. El cuerpo femenino en movimiento tuvo como objetivo la contención de posibles tempestades sexuales. La moderación y la prudencia se constituyeron contra dos grandes males que acechaban a la sociedad de fines del siglo XIX: temor a la virilización femenina y temor a una sexualidad femenina autónoma, independiente y conciente. Cualquiera de estas dos posibilidades abrió la puerta a la patologización de la diferencia del cuerpo 'femenino' debido, en gran parte, a la incomodidad de ciertos grupos sociales "frente a cierto reordenamiento de las relaciones de género" (Armus, 2002, p. 15).

En definitiva, la domesticación del cuerpo 'femenino' se basó en ciertos movimientos corporales cuyas características centrales obturaron toda posibilidad de ligarlos imaginariamente con la convulsión, el desenfreno, y la incontinencia. Una lógica de 'anticontracción muscular' se impuso para las niñas y mujeres. Todos los movimientos enérgicos, todos los gestos corporales 'desproporcionados', toda agitación corporal, todos los desplazamiento asociados al desborde, todo acto corporal que implicara sacudidas 'demedidas', fueron prohibidos. Todo gesto corporal 'irracional' fue tildado de peligroso y patológico. Fue a partir de tales conceptualizaciones y simbolismos sobre la diferencia corporal y sexual que las distintas prácticas corporales -escolares y extra-escolares- gestionaron y administraron los diferentes sentidos sobre el cuerpo, la salud, la enfermedad y la sexualidad femenina. 


\section{Referencias bibliográficas}

ARMUS, D. (Ed.) Entre médicos y curanderos. Cultura, historia y enfermedad en la América Latina moderna. Buenos Aires: Norma, 2002.

BADINTER, E. ¿Existe el amor maternal? Historia del amor maternal. Siglos XVIII al XX. Barcelona: Paidós-Pomaire, 1981.

BARRANCOS, D. Inclusión/exclusión. Historia con mujeres. Buenos Aires: FCE, 2002.

BARRANCOS, D. Anarquismo, Educación y costumbres en la Argentina de primeros de siglo. Buenos Aires: Contrapunto, 1990.

CHAUVELOT, D. Historia de la histeria: sexo y violencia en lo inconsciente. Madrid: Alianza Editorial, 2001.

DI LISCIA, M. Médicos y maestros. Higiene, eugenesia y educación en Argentina (18801940). In: DI LISCIA, M.; SALTO, G. (Ed.) Higienismo, educación y discurso en la Argentina (1870-1940). La Pampa: Edit UNLPAM, 2004. p. 37-64.

GAY, P. La experiencia burguesa. De Victoria a Freud. Tiernas pasiones. México: FCE, 1992.

GONZÁLEZ LEANDRI, R. Curar, persuadir, gobernar. La construcción histórica de la profesión médica en Buenos. Aires, 1852-1886. Madrid: CSIC, 1999.

LAVRIN, A. Women, feminism \& social change in Argentina, Chile and Uruguay, 18901940. Nebraska: University of Nebrasca, Lincoln and London, 1998.

NARI, M. Politicas de maternidad y maternalismo politico 1890-1940. Buenos Aires: Biblos, 2004.

NARODOWSKI, M. Después de clase. Desencantos y desafios de la escuela actual. Buenos Aires: Ediciones Novedades Educativas, 1999.

NOUZEILLES, G. Ficciones somáticas. Naturalismo, nacionalismo y politicas médicas del cuerpo (Argentina 1880-1910). Buenos Aires: Beatriz Viterbo, 2000.

NOUZEILLES, G. Políticas médicas de la histeria: mujeres, salud y representación en el Buenos Aires del fin de siglo. Revista Mora, Buenos Aires, n. 5, p. 97-112, oct. 1999.

PUIGGROS, A. Sujetos, disciplina y curriculum. (1885-1916). Buenos Aires: Editorial Galerna, 1990.

SALESSI, J. Médicos maleantes y maricas. Buenos Aires: Beatriz Viterbo, 1995.

SALVATORE, R. Sobre el surgimiento del Estado médico legal en Argentina (1890-1940). Estudios Sociales, Buenos Aires, ano 11, n. 20, p. 81-114, 1. sem. 2001.

SCHARAGRODSKY, P. 'Ejercitando’ los cuerpos masculinos y femeninos. Aportes para una Historia de la Educación Física Escolar Argentina (1880-1990). In: GOELLNER, S.; JAEGER, A. (Org.). Garimpando memórias: esporte, educação física, lazer e dança. Porto Alegre: Editora da UFRGS, 2007. p. 89-102. 
VARELA, J. El nacimiento de la mujer burguesa. Madrid: La Piqueta, 1997.

Fuentes primarias

BALBASTRO, A. La mujer argentina. Tesis, Facultad de Ciencias Médicas, Universidad Nacional de Buenos Aires, Buenos Aires: Imprenta Sud-América, 1892.

GARBISO, M. El médico ante la mujer. Tesis, Facultad de Ciencias Médicas, Universidad Nacional de Buenos Aires, Buenos Aires: Imprenta La Universidad de Klingelfuss y Cía., 1889.

MARTÍNEZ, A. Relaciones de la menstruación con el sistema nervioso. Tesis, Facultad de Ciencias Médicas, Universidad Nacional de Buenos Aires, Buenos Aires: Imprenta de 'El Tribuno', 1881.

RAMOS MEJÍA, J. Higiene y educación fisica de la mujer. Tesis, Facultad de Ciencias Médicas, Universidad Nacional de Buenos Aires, Buenos Aires: 1898.

RAWSON DE DELLEPIANE, E. Apuntes sobre higiene de la mujer. Tesis, Facultad de Ciencias Médicas, Universidad Nacional de Buenos Aires, Buenos Aires: Imprenta de Pablo E. Coni e hijos, 1892.

SOLÁ, F. Kinesitherapia. Tesis, Facultad de Ciencias Médicas, Universidad Nacional de Buenos Aires, Buenos Aires: Imprenta Mackern y Mclean, 1888.

UBEDA, L. La mujer argentina en la pubertad. Tesis, Facultad de Ciencias Médicas, Universidad Nacional de Buenos Aires, Buenos Aires: Librería y Casa Editora de A. Etchepareborda, 1902.

Recebido em 28 de março de 2011 e aprovado em 27 de maio de 2011. 